\title{
Preparation, optimization and in vivo anti-inflammatory evaluation of hydroquinone loaded microemulsion formulations for melasma treatment
}

\author{
Neslihan ÜSTÜNDAĞ OKUR ${ }^{1 *}$ (D), Emre Şefik ÇAĞLAR ${ }^{2}$ (D), Ahmet Nezihi PEKCAN ${ }^{3}$ (D), \\ Mehmet Evren OKUR 4 (iD, Şule AYLA 5 (i)
}

1 Department of Pharmaceutical Technology, Faculty of Pharmacy, University of Health Sciences, İstanbul, Turkey.

2 Department of Pharmaceutical Technology, School of Pharmacy, İstanbul Medipol University, İstanbul, Turkey.

3 Department of Clinical Pharmacy, Graduate School of Health Sciences, İstanbul Medipol University, İstanbul, Turkey.

4 Department of Pharmacology, Faculty of Pharmacy, University of Health Sciences, İstanbul, Turkey.

5 Department of Histology and Embryology, School of Medicine, İstanbul Medipol University, İstanbul, Turkey.

* Corresponding Author. E-mail: neslihanustundag@yahoo.com (N.Ü.O.); Tel. +90-216-418 9616.

Received: 20 November 2018 / Revised: 11 February 2019 / Accepted: 21 March 2019

\begin{abstract}
The aim of the study is to evaluate the strengthening of penetration of the epidermis through the formulas containing hydroquinone in melasma treatment and development of alternative new carrier systems. During preparation of hydroquinone loaded microemulsions, isopropyl myristate (IPM) as oil phase, Cremophor EL, Span 20, Span 80 and Tween 20 as surfactant, ethanol as co-surfactant, distilled water as aqueous phase were used. Furthermore, in vitro drug release studies were performed. As results of the study, it was measured that conductivity between $16 \pm 2.51$ and $42.1 \pm$ 2.67, viscosity between $8.97 \pm 0.082$ and $51.76 \pm 0.04$, $\mathrm{pH}$ between $3.3 \pm 0.436$ and $5.7 \pm 0.2$ and refractive index between $1.4032 \pm 0.0002$ and $1.4299 \pm 0.0002$. Formulations showed that zeta potential between $-0.461 \pm 0.009$ and $0.359 \pm 0.223$, PDI between $0.08 \pm 0.02$ and $0.196 \pm 0.067$, and droplet size between $24.27 \pm 3.559$ and $324.9 \pm 16.8 \mathrm{~nm}$. Moreover, in vitro drug release studies showed that formulation M2 released $87.405 \%$ of the drug at the end of the $24 \mathrm{~h}$. According to results of histopathological analysis, formulations were found convenient for the usage. According to results of our study, hydroquinone loaded microemulsions can be seen as a promising alternative for the treatment of melasma disease.
\end{abstract}

KEYWORDS: Hydroquinone; melasma; microemulsion; topical; mice; skin irritation.

\section{INTRODUCTION}

Hyperpigmentation can be defined as the appearance of dark color patches on the face or other areas of the body. People who have darker skin types commonly show disorders of hyperpigmentation such as melasma and post inflammatory hyperpigmentation [1]. Melasma, which is an acquired disorder of pigmentation, can be seen as symmetric darkening on the face. Increased UV exposure, pregnancy, cosmetics, genetic factors, endocrine factors, and hormonal therapy can be considered as multifactorial etiology and influencing factors of melasma [2]. In addition to this multiple etiologies, including light exposure, hormonal influences, and family history, have been implicated in the pathogenesis of this disorder [3]. Protection from sun light and depigmentation are the main objectives of melasma therapy [4]. Common therapeutic approaches for melasma include topical hydroquinone (HQ), azelaic acid, steroids, chemical peels, and lasers, most of which could not induce remarkable and constant satisfying outcomes $[4,5]$. The retardation of proliferations of melanocytes, the inhibition of melanosome formation and melanin synthesis, and the enhancement of melanosome degradation are various steps of the melanogenesis pathways which is achieved by chemical interfering in terms of pigment reduction [6].

Hydroquinone (HQ; dihydroxybenzene) is widely known and administered drug for the treatment of melanosis and other hyperpigmentary disorders [1,7]. It is structurally similar to precursors of melanin [8]. $\mathrm{HQ}$ is a hydroxyphenolic chemical and the main mechanism of the compound is inhibition of dopa conversion to melanin by inhibiting the tyrosinase enzyme [9].

How to cite this article: Üstündağ Okur N, Çağlar EŞ, Pekcan AN, Okur ME, Ayla Ş. Preparation, optimization and in vivo evaluation of hydroquinone loaded microemulsion formulations for melasma treatment. J Res Pharm. 2019; 23(4): 662-670. 
Microemulsions are homogeneous, transparent; thermodynamically stable dispersions optically isotropic liquid system of oil and water, stabilized by a suitable surfactant and cosurfactant [10]. They have several pharmaceutical advantages, such as ease of preparation, transparency and potentials for solubilizing variety of drugs [11]. Microemulsions plays important role to deliver drugs to patients in several ways but one of the most important ways of delivering drug to patients by using microemulsion is topical application [12]. It is used as a topical preparation in various concentrations from $2-5 \%$ (higher concentration may be more effective, but associated with erythema, skin peeling, irritant contact dermatitis, hypopigmentation of the surrounding skin, development of milia, and exogenous ochronosis) [13].

Dermal drug delivery has been an encouraging way of drug application for a long time since skin is easy for drug to be administered, has an enlarged surface area with vast exposure to the circulatory and lymphatic networks and the route is noninvasive [11]. Topical drug delivery is an important way of treating especially local diseases due to the features of these systems such as being restricted to the affected area, therefore, reducing systemic side effects and being easy to stop treatment in a proper time in case of a severe side effect [14].

In our study, we aimed to develop and evaluate the strengthening of penetration to the epidermis of the hydroquinone $(\mathrm{HQ})$ loaded new alternative drug carrier systems for the treatment of melasma. To ratify the dermal administration of microemulsion formulations, we histopathologically examined the dorsal skin of microemulsion treated mice and compared it to that of control groups treated with either the drug solution or serum physiologic solution (SS).

\section{RESULTS AND DISCUSSION}

\subsection{Preparation of HQ loaded microemulsion formulations}

For the preparation of microemulsions, IPM was selected as oil phase. Permeation enhancing effect of IPM is very strong and it can increase the diffusion coefficient in skin [15]. In addition, to prepare microemulsions, high concentration of surfactants and co-surfactants are necessary to develop pseudoternary phase diagrams and latter to determine the microemulsion area. This is the reason why determining the dermal tolerance of these systems is an important procedure to eliminate the possibility of irritation. In order to prepare microemulsions which have ideal formulation characteristics, Span 20, Span 80, Tween 20 and Cremophor EL as nonionic surfactants that are considered as less toxic compared to ionic ones were investigated for their suitability to form a microemulsion [16]. Meanwhile, ethanol, which is commonly used in dermal microemulsions, was used as a cosurfactant to prepare HQ loaded microemulsions.

In order to prepare ideal microemulsions, the optimum concentration range of components involved in microemulsion itself should be determined. Microemulsions were successfully prepared by pseudoternary phase diagrams. The construction of phase diagrams makes it easy to find out required concentration range of components. In order to obtain appropriate concentrations ranges of the components to form microemulsions, pseudo-ternary phase diagrams were used. Gravity center of phase diagrams provided the percentage of components in order to prepare the drug free microemulsion formulations (Figure 1). It was seen that all formulations were formed clear and transparent. Compositions of microemulsion formulation according to the pseudo-ternary phase diagrams and area values were presented in Table 1. Hydroquinone is soluble in alcohol solvents such as ethanol and methanol [17]. M1 and M2 microemulsions contain ethanol as co-surfactant. When the drug was uploaded into the microemulsion, clear microemulsion was obtained.

Table 1. Contents and percentage of prepared microemulsion formulations (M1, M2).

\begin{tabular}{ccc}
\hline Component (\%) & M1 & M2 \\
\hline IPM & 36.32 & 18.73 \\
Cremophor EL & 4.32 & - \\
Span 20 & - & 25.17 \\
Span 80 & 10.80 & - \\
Tween 20 & - & 13.98 \\
EtOH & 45.40 & 19.52 \\
Water & 3.16 & 22.60 \\
Surf/Cosurf Ratio & $1: 3$ & $2: 1$ \\
HLB & 6.65 & 11.49 \\
\hline
\end{tabular}




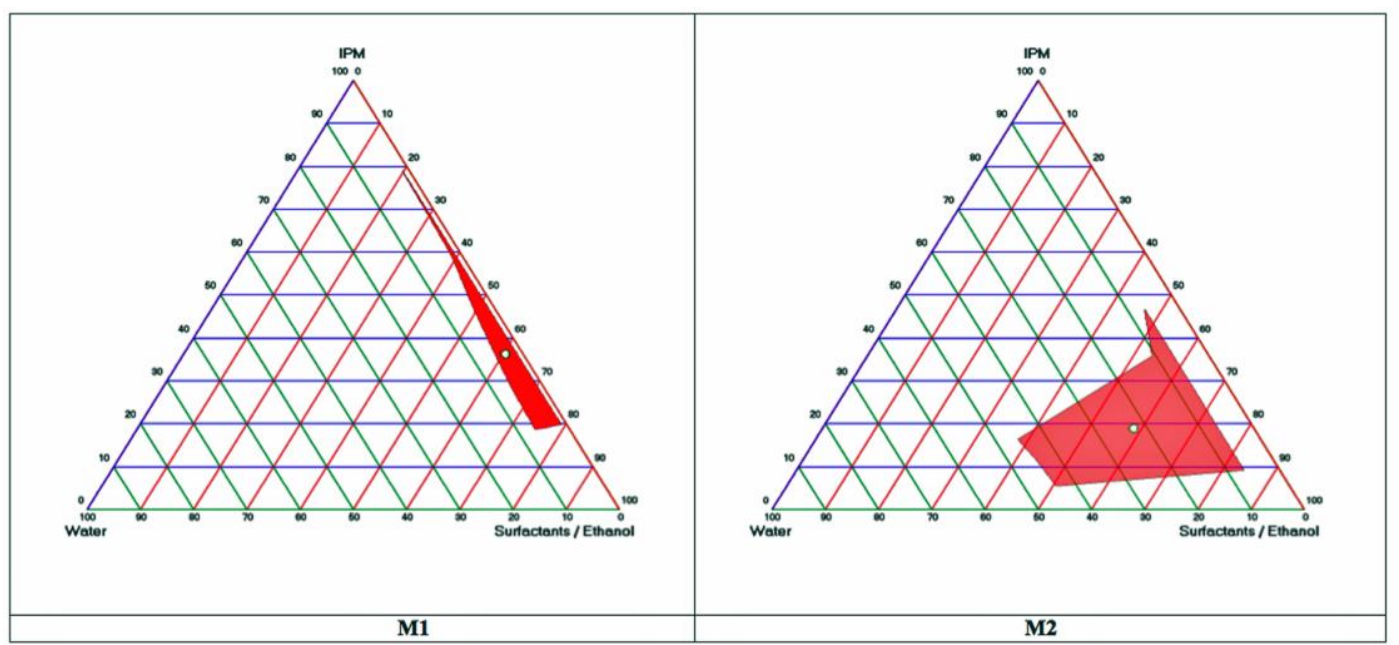

Figure 1. The pseudo-ternary phase diagrams of microemulsion formulations (M1, M2).

Concentration of $2-4 \% \mathrm{HQ}$ is prominently used as a mono-therapy or in a combination cream. Furthermore, due to irritation, preparations involving $\mathrm{HQ}>5 \%$ are not recommended except for refractory cases [18]. HQ was loaded $4 \%$ concentration in the developed microemulsion formulations. This concentration was appropriate for dermal usage. To evaluate stability drug loaded microemulsion formulations were stored in the refrigerator $\left(4 \pm 1^{\circ} \mathrm{C}\right)$ for 3 months. It was found that there were no changes in visual appearance and clarity after 3 months for M2 formulation. In addition to this no indication of aggregation or precipitation was observed. After 3 months, color of M1 formulation was changed. According to the stability studies, M2 formulation can be stored at $4 \pm 1{ }^{\circ} \mathrm{C}$. Hydroquinone, a well-known antihyperpigmentation agent suffers from instability due to rapid oxidation [1]. For this reason, researchers aimed to increase the stability of Hydroquinone using formulation strategies. An antioxidant system, most commonly the combination of sodium sulfite and sodium metabisulfite, is added to HQ formulations to stabilize HQ, which is otherwise sensitive to oxygen and light. Because oxidation of HQ increases with increasing $\mathrm{pH}$, the $\mathrm{pH}$ of $\mathrm{HQ}$ products is maintained within an acidic range ( $\mathrm{pH}$ 3.0-5.5) [19]. There is also a patent named 'Process for stabilizing hydroquinone'. The natural $\mathrm{pH}$ for conventional hydroquinone compositions is acidic, generally less than about 4 even though this is harsh to the skin and to other components of the product. This range of $\mathrm{pH}$ has been preferred for hydroquinone compositions, because it has been believed that the hydroquinone is less likely to excessively discolor under acid conditions [20]. This is the reason why HQ loaded M2 microemulsion was stable at $4 \pm 1{ }^{\circ} \mathrm{C}$ in the refrigerator for 3 months its $\mathrm{pH}$ was between 3.3-3.6.

\subsection{Characterization of microemulsion formulations}

Physicochemical characterization of microemulsion formulations especially for dermal application is an important issue to be considered in the formulation stage. Droplet size, polydispersity index (PDI), zeta potential, $\mathrm{pH}$, viscosity, refractive index and electrical conductivity were measured in terms of determining the physicochemical properties of each microemulsion. Table 2 shows the physicochemical parameters and characteristic features of microemulsions during the presence and the absence of $\mathrm{HQ}$.

Table 2. Conductivity, polydispersity index (PDI), zeta potential, mean droplet size, viscosity, $\mathrm{pH}$ and refrective index values of the developed blank and HQ loaded microemulsion formulations (Mean \pm S.D., $n=$ 5).

\begin{tabular}{lcccccc}
\hline $\begin{array}{l}\text { Microemulsion } \\
\text { code }\end{array}$ & $\begin{array}{c}\text { Conductivity } \\
(\mu \mathrm{s} / \mathbf{c m})\end{array}$ & $\begin{array}{c}\text { Zeta } \\
\text { potential } \\
(\mathbf{m V})\end{array}$ & PDI & $\begin{array}{c}\text { Droplet } \\
\text { Size }(\mathbf{n m})\end{array}$ & $\begin{array}{c}\text { Viscosity } \\
(\mathbf{c P})\end{array}$ & $\begin{array}{c}\text { RH } \\
\text { index }\end{array}$ \\
\hline M1 & $18 \pm 2.51$ & $-0.402 \pm 0.03$ & $0.196 \pm 0.06$ & $24.2 \pm 3.55$ & $8.97 \pm 0.08$ & $5.7 \pm 0.058$ \\
\\
M1
\end{tabular}


Clarity is one of the most crucial factors of microemulsion formulations. All developed formulations were assessed for clarity by visual observation against a black and white background, demonstrating that the clarity of all the formulations was sufficient. The $\mathrm{pH}$ of the prepared formulations without $\mathrm{HQ}$ ranged between $3.3 \pm 0.436$ and $5.7 \pm 0.058$ and $\mathrm{pH}$ of the prepared formulations with $\mathrm{HQ}$ ranged between $3.6 \pm 0.1$ and $5.7 \pm 0.2$. Among others, the formulation should present an optimum viscosity, which would allow its instillation on to the skin as a liquid. The viscosity of the prepared formulations presence and absence of HQ ranged between $8.97 \pm 0.082$ and $51.76 \pm 0.04 \mathrm{cP}$ at the room temperature. M2 microemulsion formulation is more viscous than M1 microemulsion. Shinde et al. prepared nadifloxacin loaded microemulsion formulations and these microemulsion systems were formulated into gel. They were evaluated the viscosity properties of these formulations. They found that the viscosity of microemulsion formulation gelled with Carbopol was higher, as compared to those formulations which were gelled with xanthan gum. The lower viscosity of xanthan gum microemulsion formulation could be attributed to ease of spreading. This was confirmed in a spreadability test where in xanthan gum microemulsion formulation showed larger diameter compared to Carbopol microemulsion formulation [21]. In another study, Zala et al. developed acyclovir loaded microemulsion formulation. The microemulsion system was investigated for viscosity, $\mathrm{pH}$, refractive index, electrical conductivity. They were found that the viscosity is around $73.3 \mathrm{cps}$ which provides sufficient adherence to skin [22].

The refractive index of the prepared formulations presence and absence of HQ ranged between 1.4032 \pm 0.0002 and $1.4299 \pm 0.0002$. There is no significant difference was determined between refractive index values of microemulsion formulations. The homogeneity of the droplet size is described by using the polydispersity value. All polydispersity values were seen smaller than 0.3 . According to these results, it was indicated that the droplet size had high homogeneity. The average conductivity of microemulsions ranged from $18 \pm 2.51$ to $42.1 \pm 2.67 \mu \mathrm{s} / \mathrm{cm}$. There was a strong correlation between the specific structure of the microemulsion systems and their electrical conductive behavior [23]. The phase systems $(\mathrm{o} / \mathrm{w}$ or $\mathrm{w} / \mathrm{o})$ of the microemulsions were determined by measuring the conductivity of the microemulsions. According to the conductivity measurements, M1 and M2 formulations were detected as w/o phase systems.

\subsection{Evaluation of in vitro $\mathrm{HQ}$ release}

The samples were analyzed by UV-Visible spectrophotometer (UV-1800, Shimadzu, Japan) at $289 \mathrm{~nm}$. The analytical method was validated in terms of analyzing the samples. Calibration curve was created with eight-point calibration concentration with the range of $0.00125-0.065 \mathrm{mg} / \mathrm{mL}$ for standard solution of bulk $\mathrm{HQ}$. Three independent determinations were performed at each concentration. Linear relationship between absorption and concentration of HQ was observed. The standard deviation of the slope and intercept were low. The determination coefficient $R^{2}$ for regression line is 0.99975 with slope of $20.1 \mathrm{x}$ and $\mathrm{y}$ - intercept of + 0.0044 for standard solution of HQ. HQ loaded microemulsion formulations and HQ loaded cream were studied for in vitro release through synthetic membrane to assess and compare the performances of formulations. Figure 2 shows the in vitro release graphics. As it can be seen in Figure 2, M2HQ shows $87.405 \%$ release at the end of the 24 th hour.

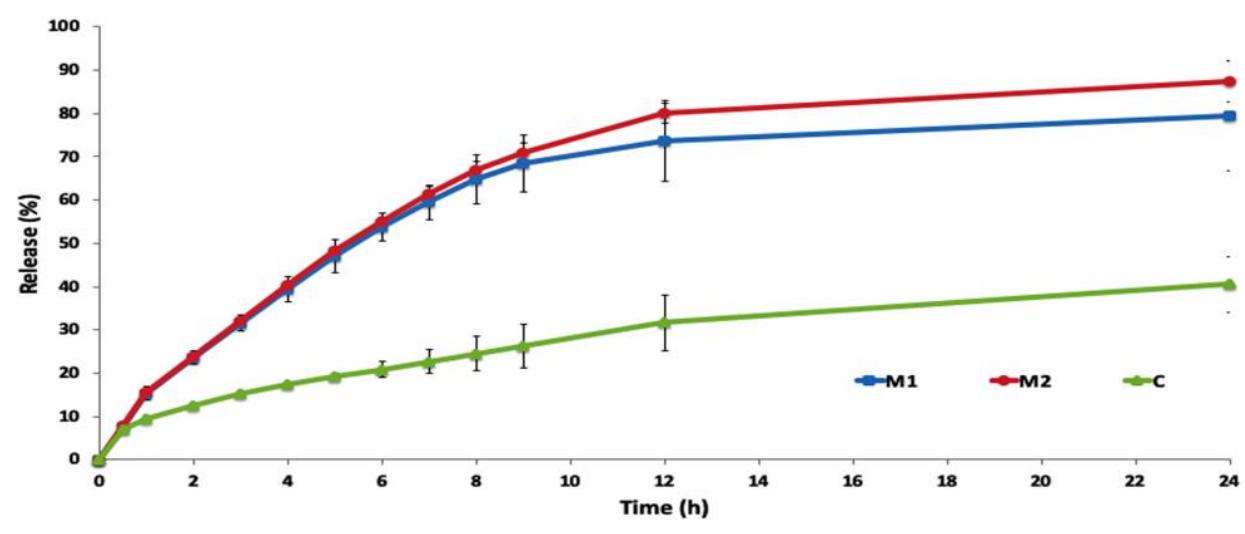

Figure 2. Percentage of drug release from HQ loaded microemulsion formulations (M1 and M2), HQ loaded cream $(\mathrm{C})$. 


\subsection{Skin irritation study}

The influence of the formulations on skin irritation was examined by topically applying them. Microscopic images of mice dorsal skin treated with the formulations (M1HQ, M2HQ, CHQ and SHQ) and SS are shown in Figure 3. Disruption degrees of epidermal layers and inflammation degrees of dermal layers for chosen drug loaded formulations and control group were evaluated as weak, moderate and severe (Table 3). HQ $4 \%$ is indicated for the gradual treatment of ultraviolet (UV)-induced dyschromia as well as hyperpigmentation resulting from pregnancy, hormone replacement therapy, skin trauma, or the use of oral contraceptives [24]. Effective HQ bleaching products, usually $2 \%$ to $4 \%$ HQ creams, often cause irritation, especially during prolonged courses of treatment [19]. The irritancy associated with HQ hinders patient compliance and may ultimately limit its benefits. When drug was incorporated in the microemulsion system, the irritancy was decreased with M1 and M2 microemulsions.

Table 3. Degradation degrees of epidermal layers and inflammation degrees of dermal layers. SC, SL, SG, SS, SB, S. papillare and S. reticulare are standing for Stratum corneum, Stratum lucidum, Stratum granulosum, Stratum spinosum, Stratum basale, Stratum papillare and Stratum reticulare, respectively.

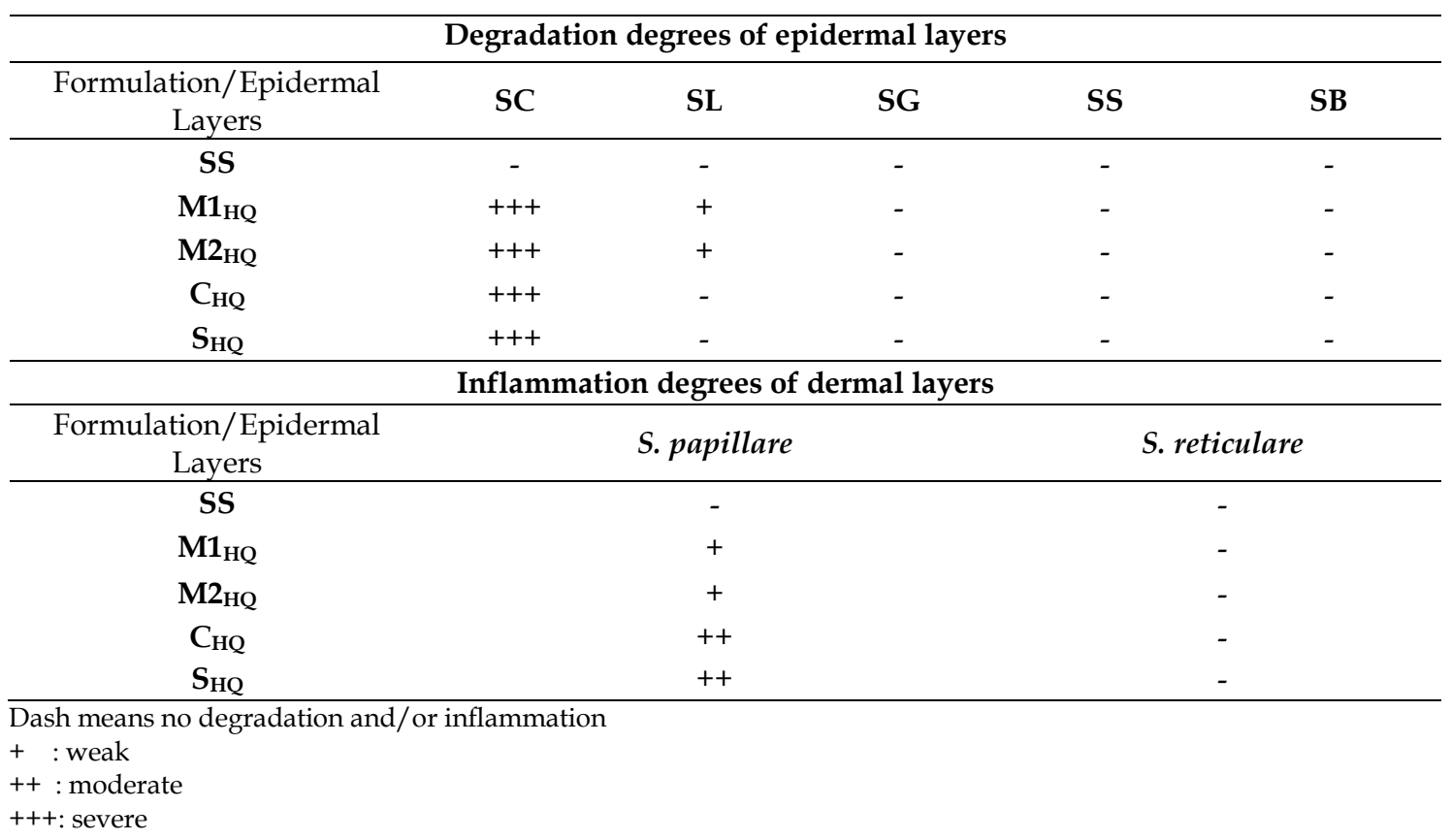

According to the results of histopathological analysis (Figure 3), the stratum corneum layer turned thinner after administration of the formulations; nevertheless, any visible difference in skin morphology after 24 th $\mathrm{h}$ is not observed.

\begin{tabular}{|c|c|c|c|c|c|}
\hline $\begin{array}{c}\text { Formulation/ } \\
\text { Magnification Value }\end{array}$ & SS & $\mathrm{Ml}_{\mathrm{HQ}}$ & $\mathrm{M}^{\mathrm{HQ}}$ & $\mathrm{C}_{\mathrm{HQ}}$ & $\mathrm{S}_{\mathrm{HO}}$ \\
\hline $10 \mathrm{X}$ & & & & & \\
\hline $20 \mathrm{X}$ & & & & & \\
\hline $40 \mathrm{x}$ & & & & & \\
\hline
\end{tabular}

Figure 3. Formulation (SS, $\mathrm{M}_{\mathrm{HQ}}, \mathrm{M}_{\mathrm{HQ}}, \mathrm{C}_{\mathrm{HQ}}, \mathrm{S}_{\mathrm{HQ}}$ ) applied mice skin. 10x, 20x, 40x (magnification value), H\&E (Hematoxylene and Eosin). 


\section{CONCLUSION}

In this study, HQ loaded microemulsions were successfully prepared via pseudo ternary phase diagrams in order to be used against melasma. The clarity, $\mathrm{pH}$, viscosity, droplet size, PDI value and zeta potential of M2 formulation was found to be satisfactory. In addition, the formulation was found stable for 3 months. Finally, histopathology investigations, after HQ loaded microemulsions application, did not show significant skin irritation in epidermis and dermis. According to results of this study, hydroquinone loaded microemulsions especially M2 can be seen as a promising alternative for the treatment of melasma disease.

\section{MATERIALS AND METHODS}

\subsection{Materials}

HQ was purchased from Doğa İlaç, Turkey. Isopyropyl myristate (IPM), Span 80, Span 20 and phosphate buffer tablets were purchased from Sigma, USA. Tween 80 (Polysorbate 80), Tween 20 and ethanol were purchased from Merck, Germany. Cremophor EL (Macrogolglycerol ricinoleate) kind gift from BASF, Germany. Dialysis membrane (Spectro/por Dialysis Mebrane, Spectra/por 4, diameter $16 \mathrm{~mm}$, molecular weight of 12-14 kDa) were purchased from Spectrum. All other chemical reagents and solvents were analytical grade and used as received. Distilled water was used throughout the study.

\subsection{Preparation of microemulsion formulations}

The existence range of microemulsions was understood by using pseudo-ternary phase diagrams. Titration method was used to obtain microemulsions. A series of oil and surfactant/cosurfactant (S/Cos) mixtures at ambient temperature $\left(25 \pm 2{ }^{\circ} \mathrm{C}\right)$ at $750 \mathrm{rpm}$ were titrated by distilled water. After being equilibrated, microemulsions were determined by visually examining the mixtures. A software program which is called Triangle Phase Diagram Analysis Software was used to construct the phase diagrams [10]. All experiments were repeated at least four times. Two different microemulsion formulations were prepared in accordance with the microemulsion areas in the phase diagrams. For the preparation of hydroquinone loaded microemulsions, isopropyl myristate as the oil phase, Cremophor EL, Span 20, Span 80 and Tween 20 as surfactant, ethanol as co-surfactant, distilled water as aqueous phase were used. After gently equilibrating selected microemulsions for $5 \mathrm{~min}$ with magnetic stirring, appropriate amount of $\mathrm{HQ}$ was dissolved in these microemulsions. The final concentration of $\mathrm{HQ}$ in formulations was $4 \%(w / w)$. The drug loaded formulations were packed in vial and stored at $4 \pm 1^{\circ} \mathrm{C}$ in the refrigerator for 3 months.

\subsection{Characterization of microemulsion formulations}

In order to find out the suitability of microemulsions for topical administration, formulations were evaluated for their characteristic features such as $\mathrm{pH}$, viscosity, refractive index, electrical conductivity, droplet size, polydispersity index (PDI), and zeta potential.

Dynamic Light Scattering method (Nano ZS, Malvern Instruments, U.K.) was used to measure the average droplet size and PDI. Experiments to measure the particle size and PDI values were repeated five times at 25 ${ }^{\circ} \mathrm{C}$. The results were obtained by averaging of five measurements at an angle of $173^{\circ}$ by using disposable cells [25]. In order to measure the zeta potential of samples, disposable plain folded capillary zeta cells (Malvern Zetasizer Nano ZS) were used. By using the Helmholtz-Smoluchowski equation, the zeta potential was calculated from the electrophoretic mobility under an electrical field of $40 \mathrm{~V} / \mathrm{cm}$. Software involved system was used for the process. The measurements were repeated five times at $25 \pm 2{ }^{\circ} \mathrm{C}$.

In order to measure the viscosities of formulations at room temperature, AND Vibro Viscometer- SV10 was used. A digital pH-meter (Mettler Toledo, Switzerland) was used to measure the $\mathrm{pH}$ values of the formulations [26]. Measurements for the refractive index values of formulations were performed by using a refractometer (Krüss DR301-95, Germany). In order to determine the type of microemulsions, electrical conductivity studies were performed by using a conductometer (Milwaukee MW 801, USA). Experiments were performed at $25 \pm 2{ }^{\circ} \mathrm{C}$ five times for each sample, and the results are presented as mean $\pm \mathrm{SD}$.

\subsection{Evaluation of in vitro $\mathrm{HQ}$ release}

A synthetic membrane (Spectro/por Dialysis Mebrane, Spectra/por 4, diameter $16 \mathrm{~mm}$, molecular weight of $12-14 \mathrm{kDa}$ ) was filled with $10 \mathrm{ml} \mathrm{HQ}$ loaded microemulsion and cream formulations. For the preparation of cream formulation, $4 \%$ of HQ dissolved in ethanol (14\%) and latter $14 \%$ of castor oil melted and stirred at $65^{\circ} \mathrm{C}$ and mixed with HQ dissolved ethanol. After that, $36 \%$ of hydrophilic ointment was 
added to the mixture and stirred once all bubbles were gone. After this step, 32\% of distilled water was added to the mixture and stirred. The receiver compartment $(90 \mathrm{~mL})$ consisted of ethanol and PBS pH 7.4 (ratio of 35:65) in order to ensure sink condition. Ambient temperature was provided for the receptor compartment and it was covered with parafilm to prevent the evaporation of the components of microemulsions. The temperature of the receptor compartment was maintained at $37 \pm 1^{\circ} \mathrm{C}$. Buffer solution in the receptor compartment was stirred at 600rpm continuously with a magnetic bar. Samples $(1 \mathrm{~mL})$ were withdrawn from the release medium at predetermined times $(0,0.5,1,2,3,4,5,6,7,8,9,12$ and 24h). UVVisible spectrophotometer (UV-1800, Shimadzu, Japan) was used to analyze the samples at $289 \mathrm{~nm}$. Afterwards, buffer solution in the receptor compartment was changed with the fresh buffer solution and calculation was performed cumulatively. The analytical method was validated. Calibration curve was drawn [27].

\subsection{Skin irritation study}

\subsubsection{Animal models and vivarium housing conditions}

Confirmation of safety profiles of prepared microemulsion and cream formulations is an important and a necessary step for the development of useful formulations. In this regard, skin irritations study was performed for these formulations. The protocol of the study was approved by Institutional Animals Ethical Committee (approval number 10.11.2017-69). For skin irritation experiment, healthy BALB-c mice were used. Mice were kept in a room at $22 \pm 2{ }^{\circ} \mathrm{C}$ with rotating 12-h light/dark cycle and they had free contact with food and water ad libitum. 1 hour before the experiment, mice were moved to the laboratory where the experiment would perform. All tests were completed between 09:00 and 12:00 $\mathrm{h}$ in normal room light and temperature $\left(22 \pm 1^{\circ} \mathrm{C}\right)$. Mice were divided into five groups: HQ loaded microemulsion 1 (M1HQ), HQ loaded microemulsion 2 (M2HQ), HQ loaded cream (CHQ), HQ solution (SHQ), and Control group [serum physiologic solution, (SS)]. Histopathological analysis of the formulations on mice skin was carried out. Before the experiment, a razor was used to shave the dorsal skin of the mice. No apparent cuts or injuries were seen after the shaving of dorsal skin. Formulations, serum physiologic solution and drug solution itself were topically administered to mice dorsal skin for $24 \mathrm{~h}$. Mice were sacrificed with anesthetic ether at the end of 24th h [28].

\subsubsection{Histopathology examination}

Dorsal skin of the animals was excised. The subcutaneous fat and connective tissue were separated. The skins were wiped off with tissue paper and fixed in formalin solution $10 \%$ in saline for one day; afterward washed with water, dehydrated with ethanol, immersed in xylene and were lastly embedded in paraffin wax at $56^{\circ} \mathrm{C}$. Paraffin blocks were cut at $5 \mu \mathrm{m}$ with a rotary microtome. Sections were stained with Hematoxylene \& Eosine and examined using the light microscope (Nikon Eclipse Ni research microscope) [29].

Author contribution: Concept - N.Ü.O.; Design - N.Ü.O.; Supervision - N.Ü.O.; Materials - N.Ü.O., E.Ş.Ç., A.N.P., M.E.O., Ş.A.; Data Collection and/or Processing - N.Ü.O., E.Ş.Ç., A.N.P., M.E.O., Ş.A.; Analysis and/or Interpretation -N.Ü.O., E.Ş.Ç., A.N.P., M.E.O., Ş.A.; Literature Search - N.Ü.O., E.Ş.Ç.; Writing - N.Ü.O., E.Ş.Ç., M.E.O.; Critical Reviews - N.Ü.O., E.Ş.Ç., A.N.P., M.E.O., Ş.A.

Conflict of interest statement: The authors declared no conflict of interest.

\section{REFERENCES}

[1] Ghanbarzadeh S, Hariri R, Kouhsoltani M, Shokri J, Javadzadeh Y, Hamishehkar H. Enhanced stability and dermal delivery of hydroquinone using solid lipid nanoparticles. Colloids Surf B Biointerfaces. 2015; 136: $1004-1110$. [CrossRef]

[2] Cohen PR. Melasma treatment: A novel approach using a topical agent that contains an anti-estrogen and a vascular endothelial growth factor inhibitor. Med Hypotheses. 2017; 101: 1-5. [CrossRef]

[3] Ogbechie-Godec OA, Elbuluk N. Melasma: An up to date comprehensive review. Dermatol Ther (Heidelb). 2017; 7(3): 305-18. [CrossRef]

[4] Kim H, Moon S, Cho S, Lee J, Kim H. Efficacy and safety of tranexamic acid in melasma: a meta-analysis and systematic review. Acta Derm Venereol. 2017; 97(7): 776-81. [CrossRef] 
[5] Padhi T, Pradhan S. Oral tranexamic acid with fluocinolone-based triple combination cream versus fluocinolonebased triple combination cream alone in melasma: An open labeled randomized comparative trial. Indian J Dermatol. 2015; 60(5): 520. [CrossRef]

[6] Rigopoulos D, Gregoriou S, Katsambas A. Hyperpigmentation and melasma. J Cosmet Dermatol. 2007; 6(3): 195202. [CrossRef]

[7] Palumbo A, d'Ischia M, Misuraca G, Prota G. Mechanism of inhibition of melanogenesis by hydroquinone. Biochim Biophys Acta - Gen Subj. 1991; 1073(1): 85-90. [CrossRef]

[8] Jimbow K, Obata H, Pathak MA, Fitzpatrick TB. Mechanism of depigmentation by hydroquinone. J Invest Dermatol. 1974; 62(4): 436-449. [CrossRef]

[9] Bandyopadhyay D. Topical treatment of melasma. Indian J Dermatol. 2009; 54(4): 303-9. [CrossRef]

[10] Üstündağ-Okur N, Ege MA, Karasulu HY. Preparation and characterization of naproxen loaded microemulsion formulations for dermal application. Int J Phar. 2014; 4: 33-42. [CrossRef]

[11] Üstündağ Okur N, Çağlar EŞ, Arpa MD, Karasulu HY. Preparation and evaluation of novel microemulsion-based hydrogels for dermal delivery of benzocaine. Pharm Dev Technol. 2017; 22(4): 500-510. [CrossRef]

[12] Üstündağ Okur N, Apaydin Ş, Karabay Yavaşoğlu NÜ, Yavaşoğlu A, Karasulu HY. Evaluation of skin permeation and anti-inflammatory and analgesic effects of new naproxen microemulsion formulations. Int J Pharm. 2011; 416(1): 136-44. [CrossRef]

[13] Martins VMR, Sousa ARD de, Portela N de C, Tigre CAF, Gonçalves LMS, Castro Filho RJ de L. Exogenous ochronosis: Case report and literature review. An Bras Dermatol. 2012; 87(4): 633-636. [CrossRef]

[14] Üstündağ Okur N, Er S, Çağlar EŞ, Ekmen TZ, Sala F. Formulation of microemulsions for dermal delivery of Cephalexin. Acta Pharm Sci. 2017; 55(4): 27-40. [CrossRef]

[15] Kreilgaard M. Influence of microemulsions on cutaneous drug delivery. Adv Drug Deliv Rev. 2002; 54(Suppl. 1), S77-S98. [CrossRef]

[16] Patel J, Patel A, Raval M, Sheth N. Formulation and development of a self-nanoemulsifying drug delivery system of irbesartan. J Adv Pharm Technol Res. 2011; 2(1): 9-16. [CrossRef]

[17] Li X, Yin Q, Chen W, Wang J. Solubility of hydroquinone in different solvents from $276.65 \mathrm{~K}$ to $345.10 \mathrm{~K}$. J Chem Eng Data. 2006; 51: 127-129. [CrossRef]

[18] Haddad AL, Matos LF, Brunstein F, Ferreira LM, Silva A, Costa D. A clinical, prospective, randomized, doubleblind trial comparing skin whitening complex with hydroquinone vs. placebo in the treatment of melasma. Int J Dermatol. 2003; 42(2): 153-156. [CrossRef]

[19] Smiles KA, Dong KK, Canning MT, Grimson R, Walfield AM, Yarosh DB. A hydroquinone formulation with increased stability and decreased potential for irritation. J Cosmet Dermatol. 2007; 6(2): 83-88. [CrossRef]

[20] Wortzman MS, Gordon P, Gans E, Patel B. Process for stabilizing hydroquinone. European Patent Application. 15.04.2009 Bulletin 2009/16.

[21] Shinde U, Pokharkar S, Modani S. Design and evaluation of microemulsion gel systems of nadifloxacin. Indian J Pharm Sci. 2012; 74(3): 237-247. [CrossRef]

[22] Zala BH, Pandya RB, Prajapat MD, Ramkisham A, Parikh RK, Gobel MC. Formulation and development of microemulsion drug delivery system of acyclovir for enhancement of permeability. J Pharm Res. 2011; 4(3): $934-937$.

[23] Yue Y, San-ming L, Pan D, Da-fang, Z, Physicochemical properties and evaluation of microemulsion systems for transdermal delivery of meloxicam. Chem Res Chin Univ. 2007; 23:(1), 81-86. [CrossRef]

[24] Akhavan A, Levitt J. Assesing retinol stability in a hydroquinone $4 \% /$ retinol $0.3 \%$ cream in the presence of antioxidants and sunscreen under simulated-use conditions: A pilot study. Clin Ther. 2008; 30(3): 543-547 [CrossRef]

[25] Üstündağ-Okur N, Gökçe EH, Bozbıyık DI, Eğrilmez S, Ertan G, Özer Ö. Novel nanostructured lipid carrier-based inserts for controlled ocular drug delivery: evaluation of corneal bioavailability and treatment efficacy in bacterial keratitis. Expert Opin Drug Deliv. 2015; 12(11): 1791-807. [CrossRef]

[26] Üstündağ Okur N, Yoltaş A, Yozgatli V. Development and characterization of voriconazole loaded in situ gel formulations for ophthalmic application. Turkish J Pharm Sci. 2016; 13(3): 311-317. [CrossRef]

[27] Üstündag-Okur N, Gökçe EH, Eğrilmez S, Özer Ö, Ertan G. Novel ofloxacin-loaded microemulsion formulations for ocular delivery. J Ocul Pharmacol Ther. 2014; 30(4): 319-32. [CrossRef] 
[28] Üstündağ Okur N, Filippousi M, Okur ME, Ayla Ş, Çağlar EŞ, Yoltaş A, et al. A novel approach for skin infections: Controlled release topical mats of poly(lactic acid)/poly(ethylene succinate) blends containing voriconazole. J Drug Deliv Sci Technol. 2018; 46: 74-86. [CrossRef]

[29] Okur ME, Ayla Ş, Çiçek Polat D, Günal MY, Yoltaş A, Biçeroğlu Ö. Novel insight into wound healing properties of methanol extract of Capparis ovata Desf. var. palaestina Zohary fruits. J Pharm Pharmacol. 2018; 70(10): 1401-1413. [CrossRef]

This is an open access article which is publicly available on our journal's website under Institutional Repository at http://dspace.marmara.edu.tr. 